\title{
Can critical inquiry differ from criticism? A dialogue with current occupational science and occupational therapy schools of inquiry
}

\author{
Jessie Wilsona, Lilian Magalhães ${ }^{\mathrm{b}}$ \\ ${ }^{a}$ College of Healthcare Sciences, James Cook University, Townsville, Australia. \\ bDepartamento de Terapia Ocupacional, Universidade Federal de São Carlos - UFSCar, São Carlos, SP, Brazil.
}

\begin{abstract}
Introduction: Critical inquiry has been adopted by various academic disciplines. However, there is a lack of consistency and transparency in the way this complex theoretical and methodological position is applied in research. For novice researchers that ambiguity can lead to blurring the conceptual distinction between critical research and the act of criticizing. Objective: The purpose of this essay is to reflect on what it means to keep a critical perspective for novice researchers. Method: The concepts are explored through a personal narrative that allows authors to examine the details of their trajectory to embrace a critical perspective, which has the power to lead to change, both personal and social. Results: We explore the methodological foundations of the critical research and observe how the emotion is taken over or suppressed in the investigation process. Conclusion: We contextualize key concepts of critical investigation, examining its recent application both in occupational science and in occupational therapy.
\end{abstract}

Keywords: Critical, Methodology, Social Theory, Emotion.

\section{Pode uma análise crítica ser diferente de uma censura? Um diálogo com campos de estudo na ciência ocupacional e na terapia ocupacional}

Resumo: Introdução: A investigação crítica tem sido adotada por várias disciplinas acadêmicas. No entanto, há uma falta de coerência e transparência na forma como esta complexa posição teórica e metodológica é aplicada em pesquisa. Para os pesquisadores novatos, essa ambiguidade pode levar à indefinição da distinção conceitual entre investigação crítica e o ato de censurar ou recriminar algo. Objetivo: Este ensaio visa a refletir sobre o que significa manter uma perspectiva crítica, para pesquisadores iniciantes. Método: Os conceitos são explorados através de uma narrativa pessoal, que permite que os autores examinem os detalhes de suas trajetórias ao abraçarem uma perspectiva crítica, que tem o poder de levar à mudança, tanto pessoal quanto social. Resultados: Exploramos os fundamentos metodológicos da investigação crítica e examinamos como a emoção é assumida ou excluída nos processos de investigação. Conclusão: Contextualizamos os conceitos-chave de investigação crítica, examinando a sua aplicação recente tanto na ciência ocupacional quanto na terapia ocupacional.

Palavras-chave: Crítica, Metodologia, Teoria Social, Emoção.

Corresponding author: Lilian Magalhães, Departamento de Terapia Ocupacional, Universidade Federal de São Carlos, Rodovia Washington Luís, Km 235, SP-310, CEP 13565-905, São Carlos, SP, Brazil, e-mail: lmagalhaes@ufscar.br 


\section{Introduction}

Critical research is a theoretical and methodological approach that is being utilized by a number of different disciplines in academia. Researchers, students and the public alike in an attempt to view the nature of the world from a fresh and informed perspective are adopting the term critical. However, with the explosion of this concept comes the increase in the vagueness of its definition and its associated tenets. For novice researchers the notion of viewing the world from a critical perspective is muddied, unclear and in many ways intimidating. Due to the discrepancies in the use of critical inquiry by many researchers, studies exist in a state of confusion, lack consistency and in many cases are inaccurate (FONTANA, 2004). With the blurred boundaries around the definition and tenants of critical science, one has to raise the question of how would critical inquiry differ from mere criticism? The word criticism has a negative connotation in today's society and it is often associated with uncontrolled emotional responses or feelings toward a topic. In academia there are unwritten rules about the role of emotion in research and the acceptability of critique among researchers and students (DE MARRAIS, 2004). It is important to expose the differences and the similarities between the notions of holding a critical perspective vs. criticizing another individual's work. This will allow for a deeper understanding of critical inquiry and its place within academia. The purpose of this paper is therefore to reflect on what it means to hold a critical perspective. Firstly, we will briefly summarize critical theory and what constitutes a critical methodological position in qualitative research. Then we will attempt to explore how emotion is used or not used in conducting and appraising research, as well as explore its ties with criticism. Then occupational science and occupational therapy literature will be examined to help frame how critical theory is being utilized in these fields of research. Finally some perspectives on the incorporation of this theoretical lens and methodological position into research and daily perspectives on occupation will be presented.

\section{The beginning of this dialogue}

When the first author (JW) attended a seminar that focused on providing therapeutic services to individuals in impoverished countries there was an invitation for the audience to reflect on a music video that the presenter had shown related to the topic of world unity and peace. As a PhD student, JW had been told that school is the place for open dialogue, for the chance to share one's unique perspective and to engage in challenging discussion. Thus JW seized the opportunity to share her opinion, which at the time she thought approached the video from a critical perspective. As the room grew quiet and she sat by listening to the presenter inaccurately paraphrase her comments to reflect an emotional dislike of the video and frame her as an individual who was criticizing the artists, JW came to the realization that maybe her notions of what it means to be a critically aware researcher was incorrect. As a $\mathrm{PhD}$ student (doctoral) in the field of occupational science, she was in process of learning about methodological positions, theoretical lenses and attempting to understand how these components contribute to conducting sound qualitative research. After leaving the seminar JW was faced with the question; what is the difference between being critical and criticizing? This paper is JW's quest to find answers through a transparent, reflexive and scholarly informed dialogue.

\section{Critical inquiry and critical theory}

Critical theory is a methodological, theoretical and philosophical position that is expansive and multifaceted. Through this paper we hope to highlight some key aspects of critical theory and critical inquiry that helped to guide our understanding of its diverse and complex components.

It is has been acknowledged that Karl Marx (1818-83) laid the foundation for critical inquiry and for today's modern critical theory (FONTANA, 2004). Marx's notions of action and change are firmly grounded in concrete social reality (CROTTY, 1998). Marx believed that social order causes illusions that function to maintain oppression (MARX; ENGELS, 1970; WOOD, 2013), as such, Marx focused on historical materialism, economic hegemony and the reoccurring notion of social class struggle; all of which mirror many tenets of today's modern critical theory. The Institute for Social Research commonly known as the Frankfurt School, was established in 1924 (CROTTY, 1998). The social philosophy of the school was an alternative to the prevailing positivist paradigm and brought together a number of different academics who shared a critical approach to their study of society (CROTTY, 1998). The school was founded with the purpose of "[...] establishing a context for the discussion of Marxist ideas [...]" (CROTTY, 1998, p. 125). It should be noted that the Frankfurt School had a turbulent history that lead to various interpretations and adaptations to the classical Marxist thought. The term "critical 
theory" was born out of the need to articulate philosophical construct and empirical detail, to create a theory that does not just merely reflect on the current social situation but one that actually seeks to change it (CROTTY, 1998). After Marx, other influential individuals such as Habermas and Paulo Freire contributed greatly to the growth and maturation of modern critical theory.

Jürgen Habermas is a German sociologist and philosopher who joined the Frankfurt School in the 1950 s as a research assistant (FONTANA, 2004). Habermas strived to expose concealed oppression and domination, analyze hidden power structures and was committed to liberating change (FONTANA, 2004). Habermas described emancipation as a process achieved through mutual understanding, communicative competence and critical reflection (FONTANA, 2004; HABERMANS, 1984). He stressed the importance of language as a form of communicative action and sought to discover and explain understanding through universal pragmatics (CROTTY, 1998). Habermas was able to move critical inquiry beyond philosophical contemplation and bring to light the importance of communicative understanding where the intent of the dialogic exchange is transparent with the aim of equality and finding truth (HABERMANS, 1984). Through this form of communicative exchange individuals are able to raise their political and moral concerns and defend them on the basis rationality alone (CROTTY, 1998). Habermas opposed rational and functionalist reason and highlighted the effect that power has on the situation of discourse (CROTTY, 1998). When reflecting on Habermas' contributions to critical theory, one can understand the importance of critical reflection in the assessment of research and discourse. Further, the value in taking the time and thinking about knowledge and its associated social structures must be reassured. It is important to look beyond the superficial exteriors and to develop an opinion based on what one hears, reads and experiences. Habermas encourages individuals to use speech as a medium in which to communicate their personal thoughts and empowers people to recognize the value of voicing their opinions that might be born out of a place of emotion and rationality.

Paulo Freire was a Brazilian educationalist that launched literacy programs among peasant people in north-east Brazil in the 1960s (CROTTY, 1998; MAGALHAES, 2012). He strongly believed that people must emancipate themselves through critical consciousness and active reflection. Freire wanted the people of Brazil to feel as though they had power over their words and had the ability to exercise power over them (CROTTY, 1998). Freire saw the educator as the student's partner, who engaged in critical thinking together in the attempt to achieve a mutual humanisation (CROTTY, 1998). He viewed people as not only 'in' the world but 'with' the world, essentially related to it in a bi-directional relationship of evolution and praxis (FREIRE, 1978).

This concept of interacting with the world brought about the idea that human beings take part in shaping the very conditions for their existence. People can be seen as existing in a state of becoming, as unfinished and uncompleted beings in partnership with an unfinished reality (CROTTY, 1998). At the heart of becoming is the need for critical consciousness and action, which, is a cyclical reflective process that enables individuals to truly see their situation and place within the world (CROTTY, 1998). The ability of people to become critically conscious then enables them to take action to reach humanisation (CROTTY, 1998). Freire's contribution to critical theory has greatly influenced the scholarship on how critical inquiry is related to education and human-world partnerships. His idea that students and teachers exist together in a partnership, speaks to the levelling of power imbalances within academia and acknowledges that growth and understanding comes from a place of interaction and shared dialogue. Freire's notion of human becoming reinforces the idea that there is no 'right' answer, only an opportunity for on-going interpretation and growth in one's position with and within the world.

It is apparent through the work of Marx, Habermas and Freire that there is the need to expose the underlying social structures of society and bring to light the inequalities and injustices that many people face. They speak to the empowerment of citizens through raising critical consciousness, encouraging individuals to form opinions and to find their voice within a culture of silence (FREIRE, 1972). The culture of silence is produced by those individuals in power with the aim of oppression which is perpetuated by the absence of reflective participation by those who are disempowered (FREIRE, 1972). Recognizing and understanding the contributions of the forerunners of critical inquiry, is important in understanding how modern critical theory has evolved and taken shape. The places of tension and turmoil within the development of the Frankfurt School and among its critical thinkers has pushed the boundaries of traditional Marxism. This has allowed for the growth and expansion of the philosophical and theoretical frameworks of critical theory. 


\subsection{Criticism}

Criticism is a word that is difficult to define because it has many different meanings, is often interpreted negatively and is expressed from a place of emotion. The Oxford Dictionary (OXFORD..., 2009) states that criticism is " 1 ) the expression of disapproval. 2) the assessment of literary or artistic works".

There is an apparent contrast between the two meanings of criticism however; the ability to use both of them interchangeably makes it difficult to distinguish between when and how the term is being utilized. It is also unclear when and how criticism evolves from being an assessment to the disapproval of an object, topic or idea. Emotions are often linked to the expression of criticism and are seen as a form of subjective interpretation by an individual. Emotion can be embedded within the research and, therefore, be seen as internally located, or it can be externally located as an expression of the reader's response to the research project. Research about emotion and its associated theories is extensive in the fields of psychology and sociology. However, the presence of emotion within health science literature is limited, especially when partnered with critical theory and criticism. Historically academics in the field of health sciences have made consorted efforts to remove emotion from research in order to uphold the positivistic notions of validity, reliability and bias (DE MARRAIS, 2004). The positivistic view of inquiry

[...] reflects a deification of a disembodied, disinterested scientist who engages in research without the engagement of the full self, taking particular care to excise any emotional involvement in the work [...] (DE MARRAIS, 2004, p. 285).

As such, positivistic research does not allow the researcher's emotions to enter the investigation process as it may somehow impede their claims to truth (DICKSON-SWIFT; JAMES; LIAMPUTTONG, 2008).

Quantitative researchers take the stance that "truth can transcend opinion and personal bias" (GUBA; LINCOLN, 2005, p. 8), therefore, the researcher is able to find objective truth through the research process. We do not see quantitative researchers as disinterested or who do not possess some form of emotional attachment to their work; instead we sustain that they are simply adhering to the quality criteria imposed by their paradigmatic position. It would seem impossible for any researcher despite their ontological, epistemological or paradigmatic position to not have some emotional investment in their study, or why else would a researcher devote their time to researching a topic or a phenomenon in the first place?

In contrast to the objective and emotion-free position of quantitative research, qualitative inquiry gives the investigator the opportunity to explore the complexities of the human experience intertwined with value and meaning. Although qualitative inquiry is carving out a place for itself as a legitimate contributor to the scientific knowledge base, there is still a labelling of qualitative research as being 'soft' by many individuals, institutions and funding agencies (BLAIR; ROBERTSON, 2005). Qualitative inquiry embraces the researcher's and the participant's emotional awareness; and it is through this investment in the research process that allows for the creation of rich and meaningful data. Qualitative inquiry allows the research agenda to be shaped by both the researcher and the participants, therefore, encouraging the emotional commitment from both parties (DICKSON-SWIFT; JAMES; LIAMPUTTONG, 2008). Research that deals with sensitive topics is usually conducted from a qualitative methodological position. This is because a relationship must be built between the researcher and the participants that is non-hierarchal and is built on trust and rapport (DICKSON-SWIFT; JAMES; LIAMPUTTONG, 2008). When conducting sensitive research the investigator must often invest his or her personal identity into the relationship in order to gather rich and meaningful data (DICKSON-SWIFT; JAMES; LIAMPUTTONG, 2008). One of the main critiques of allowing emotion to be present within the research process is the fear that emotion may lead the building of an over-rapport between the investigator and the participants (DICKSON-SWIFT; JAMES; LIAMPUTTONG, 2008). Constant critical reflection on the researcher-participant relationship is required to ensure the ethical and moral standards of scientific inquiry are being met and respected. Planning for withdrawal from the investigation and ensuring transparency through reflexive journaling will enable to researcher to ensure respectful and ethical relationships with the participants (CRESWELL, 2013). When reading and analyzing research studies it is important to recognize what ontological and epistemological position the investigators are conducting their research from. This is because many qualitative methodologies consider the fusion of the researchers' perspectives and interpretations with those of the participant's (from whom data is gathered) to be considered both inevitable and necessary. This transparent positioning of the researcher is very different from the involvement of the researcher when conducting a 
study from a quantitative methodological standing, which affords a somewhat neutral positionality.

\subsection{Emotion}

Emotion that is evoked in an individual after reading a research study or attending an academic conference is a fundamental part of criticism. Critiquing another individual's work is a part of the advancement of knowledge, which permeates all areas of education (SCHMELZER, 2006). Having an emotional reaction to a piece of academic work whether it is positive or negative is an innate part of human nature. Caring as a human trait has been explored extensively by Martin Heidegger (1962) who, concluded that one of the most basic ways of being in the world and being human is the experience of caring. An important principal in undertaking research aligned with a critical perspective is the acknowledgement of the link between emotion and knowledge (DICKSON-SWIFT; JAMES; LIAMPUTTONG, 2008). Emotional and cognitive functions can be seen as being inseparable from each other, as individuals often use emotion to understand the world around them (DICKSON-SWIFT; JAMES; LIAMPUTTONG, 2008). An emotional response to a piece of academic work gives individuals the foundation on which to build critical feedback. This feedback facilitates the advancement of knowledge through the exchanging of insights and perspectives. As Horton notes "[...] free expression of opinion, reveal the intellectual vigour of the community concerned, and help shape knowledge [...]" (HORTON, 2002, p. 2846). There are unwritten rules about how and when one can express emotion within their academic community. Researchers often indicate that they do not want to be perceived as too emotional, as they might send the wrong message to colleagues about their research out of fear that their opinions could be too subjective and untrustworthy (DICKSON-SWIFT; JAMES; LIAMPUTTONG, 2008). However, researchers and professionals have been socialized into academic life, which is built upon the foundation of positivistic values (DICKSON-SWIFT; JAMES; LIAMPUTTONG, 2008). This academic habitus (BOURDIEU; WACQUANT, 1992) is reinforced by the strict guidelines of publishers, research committees, funders and journal editors (DICKSON-SWIFT; JAMES; LIAMPUTTONG, 2008). Showing emotion within research or as a reaction to research can make individuals feel more vulnerable and open to judgments from colleagues and other professional agencies (DICKSON-SWIFT; JAMES; LIAMPUTTONG, 2008). There is a tension that is present then between the need for critique of a student's work vs. the critique that is avoided by researchers. Students are exposed to critical feedback throughout their academic careers, which helps to shape their learning experiences (GIBBS; SIMPSON, 2004). Literature in the field of education exhaustively investigates various models, theories and practices of how to give students critical feedback with the purpose of enhancing their academic performance. Students are taught that accepting critical feedback is a component of professional behaviour, which is required to be successful in their future career (SCHEERER, 2003). However, there is limited research regarding the value of critiquing published literature or work conducted by established researchers and academics. Correspondence columns in academic journals and open discussion after seminars and presentations offer the chance for critical dialogue about published research. These forums act as a part of the continual process of peer review, however, criticism is often undervalued by many health science researchers and practice communities (HORTON, 2002). Some argue that there is no perfect research study, therefore, post-publication peer review is a valuable asset for the advancement of science (GOTZSCHE et al., 2010). The tension that exists between giving and receiving critical feedback is deeply rooted in the power structures within an academic community.

Discussion, disagreement, and debate are necessary ingredients of scientific inquiry. Human beings have varying talents and perspectives, and a particular work is strengthened by the input from the group. We need to seek the wisdom of others, not focus on our personal pride (SCHMELZER, 2006, p. 324).

The power dynamics within science arenas in general has been well outlined. Even though this would be beyond the scope of this paper, many Occupational scientists and occupational therapy's theorists have pointed the hegemony of Westernized perspectives in the field. Critical, audacious scrutiny would be needed for such a shift, in order for theoretical frames of reference to be inclusive rather than exclusive (HAMMELL, 2011).

\section{Critical theory and criticism in occupational science and occupational therapy}

Currently a tension exists between the fields of occupational science (OS) and occupational therapy 
(OT). Two different schools of thought have developed regarding the nature of the relationship between the two disciplines. One view is that

[...] with regard to the direction of the research, we are mindful that the relationship of occupational science and occupational therapy is symbiotic and their reproductive cycles depend on the vitality of both [...] (CLARK, 2006, p. 177).

This implies that the primary focus of OS research should directly contribute to the development of OT and that OS should permeate the OT curricula and inform OT practice (CLARK, 2006). This argument arises from the notion that the OS developed out of the values and traditions of the occupational therapy profession (YERXA, 1993). Clark (2006) argues that OS and OT are intricately bound together, and that they are dependent on one another for survival. The contrasting view point to the symbiotic relationship between OS and OT is that

[...] the creation and presupposing of abstract boundaries between "applied" and "basic", the exclusion of certain types of research, and a failure to consider their interactions, may encumber new ways of thinking and knowing, and limit the research possibilities and innovations within occupational science (RUDMAN et al., 2008, p. 140).

This considers an important notion that by limiting the purpose of OS research to inform the discipline of OT, we may limit our research focus and overlook important information related to occupation. As researchers we want to ensure that were are not "viewing occupation too narrowly, through the distorting lenses of our own culture" (RUDMAN; DENNHARDT, 2008, p. 159). By narrowing our focus of occupation it may also make academics that are not OT's wary to make contributions and restrict the interdisciplinary growth of the profession (MOLKE; RUDMAN; POLATAJKO, 2004). This tension between what the purpose of OS research should serve affects all aspects of its development and growth as a discipline. It is important to recognize and reflect upon this tension in order to understand how critical theory and criticism are adopted and framed similarly and differently in fields of OS and OT.

OT can be defined as:

A client-centred health profession concerned with promoting health and well being through occupation. The primary goal of occupational therapy is to enable people to participate in the activities of everyday life. Occupational therapists achieve this outcome by working with people and communities to enhance their ability to engage in the occupations they want to, need to, or are expected to do, or by modifying the occupation or the environment to better support their occupational engagement (WORLD..., 2012, p.3).

Occupational therapists work from holistic, but yet evidenced based treatment models. Their aim is to identify occupations that are meaningful to individuals, who experience ill health or disability and assist them in developing their skills to successfully manage everyday life, or participate in their chosen occupations (CHRISTIANSEN; TOWNSEND, 2004). Occupational therapists are aware of the need to critically reflect and critique the development of the profession, student curriculum and theoretical models and foundations of practice. Due to the practical focus of OT many of the published critiques in the OT journals are focused around treatment interventions, models of care and professional practice. Evidence-based practice (EBP) has received a lot of attention in the OT literature as it is an area that is supported by government policy which seeks to inform and direct OT practice (BLAIR; ROBERTSON, 2005). EBP is seen as the mandate for the new millennium (HOLM, 2000) and is considered a professional imperative to ensure best practices in OT (BLAIR; ROBERTSON, 2005). EBP is born out of positivistic values and beliefs and has a lot of power within the field of OT. This is because EBP conforms to the more classical methodological positions which are based on rigor, objectivity and generalizability (TOMLIN; BORGETTO, 2011). The theoretical structure of EBP has not yet aligned itself with the clinical decision making of practitioners (TOMLIN; BORGETTO, 2011). This is because OTs are concerned with the lived experience of their clients and focus on the real world outcomes of spiritual, physical and social involvement which are typically overlooked in quantitative research (TOMLIN; BORGETTO, 2011). A tension has developed within the field of OT due to an increase in qualitative research that has been recently published which, seeks to inform therapists who work in situations of complexity and discontinuity, where humanistic values underpin practice (BLAIR; ROBERTSON, 2005). With the advancement of qualitative inquiry, the validity of the hierarchical model of EBP is called into question and new procedures are needed to evaluate the authenticity of qualitative research. The profession of OT is now in the process of critically reflecting on what constitutes $\mathrm{EB}$, and 
are acknowledging that there is no gold standard of research design for answering the complex and multifaceted questions that are a part of an OT's clinical practice (TOMLIN; BORGETTO, 2011).

Occupational science (OS) was formally introduced in the late 1980's and early 1990's, and was born out of the University of Southern California. Since its inception OS has expanded internationally and has become a discipline characterized by diversity (HOCKING, 2000). Diversity is found among the topics that occupational scientists choose to study, in the approaches to research which they have employed and in the characteristics and definitions of the word occupation itself (HOCKING, 2000). The interdisciplinary nature of $O S$ also encourages the emotional investment of its researchers in their areas of study. The use of critical methodologies and the proactive nature of research around occupation and health, implicitly demonstrates the involvement of emotion within much of the OS literature. The welcomed diversity in the field of occupational science adds to the richness of its culture, however, caution needs to be taken to also critically appraise the research that is being conducted to ensure that it is adding to the advancement of the discipline. Recent attention has been given to exploring the directions that are vital for the OS discipline to thrive and survive (RUDMAN et al., 2008; RUDMAN, 2014). In fact, recent scholarship has been demanding further scrutiny of critical (allegedly emancipatory) perspectives in occupational science and therapy (FARIAS; RUDMAN, 2014).

Leading this dialogue, Clark (2006) summarized the significant milestones of OS and assessed the current health of OS in comparison to the disciplines of sociology and geography whose sustainability is currently in jeopardy. Rudman et al. (2008) encouraged critical dialogue about how disciplinary culture helps to shape the identity of OS, its internationalization, its relevance to practice and its interdisciplinary nature. As Rudman (2014, p. 373) further indicates

Pushing beyond the limits of dualistic thinking; attending to the socio-political nature of occupation; addressing the moral and political values that shape and energize occupational science work; questioning the familiar and exploring the unfamiliar; and, engaging in innovative interdisciplinary syntheses.

Both occupational scientists and occupational therapists are concerned with the complex partnerships between occupation, health, quality of life, identity, social and political structures as well as between doing, being and becoming (HOCKING, 2000). Occupational justice is a term that has developed and evolved in both the occupational therapy and occupational science literature. Occupational justice is a

[...] term credited to Townsend (Canada) and Wilcock (Australia) referring to justice related to opportunities and resources required for occupational participation sufficient to satisfy personal needs and full citizenship [...] (CHRISTIANSEN; TOWNSEND, 2004, p. 278).

Occupational justice compliments social justice by offering a new lens for looking at and acting on the world from an occupational perspective (TOWNSEND; WILCOCK, 2004). Occupational justice is tightly linked with a critical social perspective and is built upon the work of both Habermas and Karl Marx. The principles of occupational justice include empowerment through occupation, inclusive classification of occupations, enablement of occupational potential, diversity and inclusion and shared advantage in occupational participation (TOWNSEND; WILCOCK, 2004).

Enablement and empowerment are two concepts that permeate all areas of occupational justice and are cohesive with Paulo Freire's notions of 'conscientization'. "Conscientization is an awakening of, or increase in consciousness" (CROTTY, 1998, p. 148) related to the enhanced critical awareness of the governing social and political forces that have an impact on an individual's life (MAGALHÁES, 2012). Enablement is focused on drawing out people's individual strengths and differences and gives them the opportunity to be involved in solving their own problems (TOWNSEND, 2003). Enablement and empowerment are based on the common foundation that humans participate in occupations as autonomous agents and occupational participation is interdependent and contextual (TOWNSEND; WILCOCK, 2004).

These foundational elements lead to action that is orientated toward shaping social and political systems and encourages self-empowerment (TOWNSEND, 2003). Self-empowerment and the process of becoming is a commonality between occupational justice, occupational science, occupational therapy and critical theory.

Freire (1972) recognizes that people are in the constant process of becoming and that through action and reflection individuals come to a place of 'humanization'. Paulo Freire incorporates many elements of existential phenomenology into his 
work (CROTTY, 1998), which is cohesive with the holistic occupational perspective that recognizes the individual's lived experience as it is embedded 'in', and in relationship 'with' the world (MAGALHAES, 2012).

The concept of occupational justice is therefore rooted within both the disciplines of occupational science and occupational therapy. It is built upon the foundation of critical theory and shares common perspectives with Habermas, Marx and Freire (TOWNSEND, 1997) related to the concepts of enablement, empowerment and the notion of becoming. Therefore the interconnected nature of these elements allows for the strengthening of the theoretical and methodological foundations of occupational therapy and occupational science.

\section{Putting these two perspectives together: looking toward the future}

Throughout this paper we have had the opportunity to reflect upon our own assumptions of what critical theory and criticism are; and how they relate to current academic and practical interests. The first perspective that resonated with us as researchers is the notion of mobile subjectivities (OGLE; GLASS, 2006). Mobile subjectivities refers to the movement between cohesive paradigmatic positions, that in turn allows the researcher to use multiple perspectives to help explicate alternative interpretations that might otherwise be overlooked (OGLE; GLASS, 2006). Mobile subjectivity permits the researcher to recognize their multiple selves as a strength therefore, allowing the process of positioning to occur interactively and reflectively (OGLE; GLASS, 2006). "The notion of mobile subjectivities aligns well with the perspective of the researcher being a bricoleur" (DENZIN; LINCOLN, 2011, p. 4). The bricoleur can be seen as an individual who finds value in consciously pulling together different tools and techniques to help answer their research question in the most authentic and meaningful way (DENZIN; LINCOLN, 2011).“The choice of research practices depends upon the questions that are asked, and the questions depend on the context" (NELSON; TREICHLER; GROSSBERG, 1992, p. 2). The perspectives of the bricoleur and the mobile subjectivist are in tension with the modernistic ideal of a unified and rational positivistic position to research, that focuses on the objective reality and the generalizability of knowledge. However, we sustain that there is value in this form of post-modern positioning that encourages the researcher's reflection and acknowledgement of the complexities of reality, power, language, desire and experience (OGLE; GLASS, 2006).

The second perspective that helped us to view critique through a new and positive lens is the "framework for human becoming criticism" (MITCHELL, 2004, p. 104). The framework for human becoming criticism is consistent with the human becoming school of thought, and is built upon literacy theory and the human becoming hermeneutic method (MITCHELL, 2004).

The human becoming critic enhances the original work in an artistic way, that once disseminated, opens the door for others to engage both the original work and the critical interpretation as an artistic enhancement (MITCHELL, 2004, p. 107).

The three processes that embody the framework for human becoming criticism are: sketching the horizon of understanding, illuminating artistic disclosure and enhancing the original with art form (MITCHELL, 2006). The framework for the human becoming critique is complex and deeply theoretical in nature, therefore, allowing for it to be utilized from a number of different theoretical and methodological positions. The human becoming aspect of this framework resonated with us because of its fit with the foundational beliefs and values of occupational therapy and occupational science. Through this framework the researcher writes in anticipation of critical engagement with the readers, so that new levels of understanding can be brought forth to enhance knowledge and understanding of a topic (MITCHELL, 2004). Another aspect of the framework that resonated with us was the acceptance that each reader will experience the researcher's work in a unique and personal way. The expectation is that the reader will take the time to reflect on the researcher's 'horizon of expectation' and then compare, contrast or combine it with their own distinct perspective and artistic insights (MITCHELL, 2004). Lastly we support the way in which the framework views research and the process of critique as unique art forms. "The artfulness of criticism comes to bear here when the critic engages with the art form and enhances the original product in a new way" (MITCHELL, 2004, p. 108).

This paper has intended to enter into a dialogue with novice researchers and encourage them to take the time and sit in a space of discomfort, reflect on their current understanding of critical theory and criticism and then move forward and take action 
with the intent of learning more about themselves, as well as exploring the role of critical inquiry in research and clinical practice. Through this paper we have briefly summarized the history of critical theory to enhance an understanding of this complex theoretical and methodological approach to inquiry.

Reflecting back on JW's experience during the seminar presentation, she is no longer filled with embarrassment or shame. This paper has enabled JW as a novice researcher to reflect on her current understanding of critical theory and criticism and explore more about herself as well as about the role of critical inquiry in her research and clinical practice. Finally, through her dialogue with the second author, she reflected on two perspectives that she intends to utilize in her career which are 1. incorporating the notion of mobile subjectivities or bricolage, and 2. the framework of human becoming criticism. In conclusion it is necessary to recognize that

An important element in the advancement of the knowledge base of a scholarly discipline is the discourse generated when members of the discipline engage in review and critique of theory and research publications.....Through such scrutiny, the merit and significance of these contributions to the discipline are evaluated, the gaps or inconsistencies in knowledge are identified, and questions for further inquiry are raised (PILKINGTON, 2004, p. 102).

The future seems to be promising as we fearlessly embrace critical perspectives that will lead us to social and personal change.

\section{References}

BLAIR, S. E.; ROBERTSON, L. J. Hard complexities - soft complexities: an exploration of philosophical positions related to evidence in occupational therapy. British Journal of Occupational Therapy, London, v. 68, n. 6, p. 269-276, 2005.

BOURDIEU, P.; WACQUANT, J. D. Invitation to reflexive sociology. Cambridge: Polity Press, 1992.

CHRISTIANSEN, C. H.; TOWNSEND, E. A. Introduction to occupation: The art and science of living. Upper Saddle River: Prentice Hall, 2004.

CLARK, F. One person's thoughts on the future of occupational science. Journal of Occupational Science, Melbourne, v. 13, n. 3, p. 167-179, 2006.

CRESWELL, J. W. Qualitative inquiry \& research design choosing among five approaches. Thousand Oaks: Sage Publications, 2013.
CROTTY, M. The foundations of social research meaning and perspective in the research process. Thousand Oaks: Sage Publications, 1998.

DE MARRAIS, K. Elegant communications: Sharing qualitative research with communities, colleagues, and critics. Qualitative Inquiry, Thousand Oaks, v. 10, n. 2, p. 281-297, 2004.

DENZIN, N. K.; LINCOLN, Y. S. Qualitative research. Thousand Oaks: Sage, 2011.

DICKSON-SWIFT, V.; JAMES, E. L.; LIAMPUTTONG, P. Undertaking sensitive research in the health sciences and social sciences managing boundaries, emotions and risks. Cambridge: Cambridge University Press, 2008.

FARIAS, L.; RUDMAN, D. L. A critical interpretive synthesis of the uptake of critical perspectives in occupational science. Journal of Occupational Science, Melbourne, v. 23, n. 1, p. 33-50, 2014.

FONTANA, J. S. A methodology for critical science in nursing. Advances in Nursing Science, Philadelphia, v. 27, n. 2, p. 93-101, 2004.

FREIRE, P. Pedagogy in process: the letters to GuineaBissau. London: Writers and Readers Publishing Cooperative, 1978.

FREIRE, P. Pedagogy of the oppressed. Hamondsworth: Penguin, 1972.

GIBBS, G.; SIMPSON, C. Conditions under which assessment supports student's learning. Learning and teaching in higher education, Gloucestershire, v. 1, n. 1, p. 3-31, 2004.

GOTZSCHE, P. C. et al. Adequacy of authors' replies to criticism raised in electronic letters to the editor: Cohort study. British Medical Journal, London, v. 341, p. 1-5, 2010.

GUBA, E. G.; LINCOLN, Y. S. Paradigmatic controversies, contradictions and emerging confluences. In: DENZIN, N. K.; LINCOLN, Y. S. (Org.). Handbook of qualitative research. Thousand Oaks: Sage Publications, 2005. p. 191-216.

HABERMANS, J. The theory of communicative action. Boston: Beacon Press, 1984.

HAMMELL, K. W. Resisting theoretical imperialism in the disciplines of occupational science and occupational therapy. The British Journal of Occupational Therapy, London, v. 74, n. 1, p. 27-33, 2011.

HOCKING, C. Occupational science: a stock take of accumulated insights. Journal of Occupational Science, Melbourne, v. 7, n. 2, p. 58-67, 2000.

HOLM, M. Our mandate for the new millennium: evidence-based practice. American Journal of Occupational Therapy, Bethesda, v. 54, n. 6, p. 575-585, 2000. 
HORTON, R. Postpublication criticism and the shaping of clinical knowledge. JAMA, Chicago, v. 287, n. 21, p. 2843-2847, 2002.

MAGALHÂES, L. What would Paulo Freire think of Occupational Science? In: WHITEFORD, G.; HOCKING, C. (Ed.). Occupational science: society, inclusion, participation. Oxford: Blackwell Publishing Ltd., 2012. p. 8-19. http://dx.doi.org/10.1002/9781118281581. ch2.

MARX, K.; ENGLES, F. The german ideology. New York: Random House, 1970.

MITCHELL, G. J. An emerging framework for human becoming criticism. Nursing Science Quarterly, Thousand Oaks, v. 17, n. 2, p. 103-109, 2004.

MITCHELL, G. J. Human becoming criticism- A critique of Florczak's study on the lived experience of sacrificing something important. Nursing Science Quarterly, Thousand Oaks, v. 19, n. 2, p. 142-146, 2006.

MOLKE, D. K.; RUDMAN, D. L.; POLATAJKO, H. J. The promise of occupational science: a developmental assessment of an emerging academic discipline. The $\mathrm{Ca}$ nadian Journal of Occupational Therapy, Thousand Oaks, v. 71, n. 5, p. 269-278, 2004.

NELSON, C.; TREICHLER, P. A.; GROSSBERG, L. Cultural studies: An introduction. In: GROSSBERG, L.; NELSON, C.; TREICHLER, P. A. (Org.). Cultural Studies. New York: Routledge, 1992. p. 1-16.

OGLE, K. R.; GLASS, N. Mobile subjectivities: positioning the nonunitary self in critical feminist and postmodern research. Advances in Nursing Science, Philadelphia, v. 29, n. 2, p. 170-180, 2006.

OXFORD English Dictionary. Oxford dicitionaries. Oxford: Oxford University Press. Available from: < http:// www.oxforddictionaries.com/definition/english/criticism>. Access on: 5 nov. 2015.

PILKINGTON, F. B. Human becoming criticism: a knowledge innovation. Nursing Science Quarterly, Thousand Oaks, v. 17, n. 2, p. 102, 2004.

RUDMAN, D. L. Embracing and enacting an 'occupational imagination': occupational science as transforma- tive. Journal of Occupational Science, Melbourne, v. 21, n. 4, p. 373-388, 2014.

RUDMAN, D. L. et al. A vision for occupational science: reflecting on our disciplinary culture. Journal of Occupational Science, Melbourne, v. 15, n. 3, p. 136146, 2008.

RUDMAN, D. L.; DENNHARDT, S. Shaping knowledge regarding occupation: Examining the cultural underpinnings of the evolving concept of occupational identity. Australian Occupational Therapy Journal, Richmond, v. 55, n. 3, p.153-162, 2008.

SCHEERER, C. R. Perceptions of effective professional behaviour feedback: Occupational therapy student voices. American Journal of Occupational Therapy, Bethesda, v. 57, n. 2, p. 205-214, 2003.

SCHMELZER, M. The critique: a necessary part of scientific inquiry. Gastrointestinal Nursing, Baltimore, v. 29, n. 4, p. 324-325, 2006.

TOMLIN, G.; BORGETTO, B. Research pyramid: A new evidenced-based practice model for occupational therapy. American Journal of Occupational Therapy, Bethesda, v. 65, n. 2, p. 189-196, 2011.

TOWNSEND, E. Occupation: potential for personal and social transformation. Journal of Occupational Science, Melbourne, v. 4, n. 1, p. 18-26, 1997.

TOWNSEND, E. Reflections on power and justice in enabling occupation. Canadian Journal of Occupational Therapy, Thousand Oaks, v. 70, n. 2, p. 74-87, 2003

TOWNSEND, E.; WILCOCK, A. Occupational justice. In: CHRISTIANSEN, C. H.; TOWNSEND, E. A. (Org.). Introduction to occupation the art and science of living. New Jersey: Prentice Hall, 2004. p. 243-273.

WORLD FEDERATION OF OCCUPATIONAL THERAPISTS - WFOT. Definition of occupational therapy. Australia, 2012. Available from: <http://www.wfot.org/ AboutUs/AboutOccupationalTherapy/DefinitionofOccupationalTherapy.aspx>. Access on: 5 nov. 2015.

YERXA, E. Occupational science: a new source of power for participants in occupational therapy. Occupational Science, Melbourne, v. 1, n. 1, p. 3-8, 1993.

\section{Author's Contributions}

The first author conceived the plot for the paper. Both authors prepared the manuscript and approved its final version. 